\title{
Assessment of the mechanism of drug resistance in Trichophyton mentagrophytes in response to various substances
}

Chenwen Xiao', Jiaoyu Wang ${ }^{2}$, Zhenfeng Liao ${ }^{3}$, Yee Huang ${ }^{1}$, Quanan Ji', Yan Liu', Fei Su', Lijun Xu', Qiang Wei', Yao Pan ${ }^{1,5}, \mathrm{Ke} \mathrm{Li}^{1}$ and Guolian Bao ${ }^{1 *}$

\begin{abstract}
Background: Trichophyton mentagrophyte (TM), a zoonotic pathogen, has been endangering public health due to emerging drug resistance. Although increased attention is paid to this issue, there is very limited research available on drug resistance in TM. In this study, we studied the gene and proteomic changes, morphological changes, cellular fat localization, fat content changes, and biofilm of TM treated with different substances.

Results: The TM growth curve showed a positive correlation with the concentration of Fenarimol (FE), genistein (GE), clotrimazole (KM), and Miconazole nitrate salt (MK). The morphology of TM cells changed in different degrees after treatment with different substances as observed by TEM and SEM. The results showed that under KM and berberine hydrochloride (BB) treatment, a total of 3305 differentially expressed genes were detected, with the highest number in the KM-treated group (578 up-regulated and 615 down-regulated). A total of 847 proteins and 1850 peptides were identified in TM proteomics. Nile red staining showed that the fat content of TM was significantly higher in the BB-, ethidium bromide- (EB), FE-, KM-, Adriamycin hydrochloride- (YA), and MK-treated group compared to the control group. Results of the biofilm thickness showed that it gradually increased under treatment with specific concentrations of $\mathrm{KM}$ or BB, which may be related to the up-regulation of ERG 25 and CYP related gene proteins.
\end{abstract}

Conclusions: It is suggested that in order to effectively deal with dermatomycosis caused by TM, it is necessary to inhibit the expression of ERG 25 and CYP related genes and fat metabolism, which can result in the inhibition of the production of biofilm by the fungus and solve the problem of fungal drug resistance in clinical settings.

Keywords: Trichophyton mentagrophyte, Steroid pathway, ERG25, CYP450, Transcriptome, Proteomics

\section{Background}

Trichophyton mentagrophyte (TM), a zoonotic pathogen, has been endangering public safety as dermatomycosis caused by TM is one of the most common skin diseases in the rabbit industry. It mainly damages the fur and affects its quality. In serious cases, it can lead to malnutrition,

\footnotetext{
* Correspondence: baoguolian2020@163.com

1 Institute of Animal Husbandry and Veterinary Science, Zhejiang Academy of Agricultural Sciences, Hangzhou, China

Full list of author information is available at the end of the article
}

growth retardation, and reduced feed returns, which causes great economic losses to the rabbit industry [1]. Although there are a variety of clinical drugs for the treatment of animal fungal skin diseases, including hormones, antibiotics, and antifungal drugs, they have many disadvantages, such as drug resistance with long-term use side effects [2]. At present, the mechanism of drug resistance in TM is still unclear and only a few studies on functional genes have been published [3-5]. In this study, we used different substances to evaluate the potential mechanism

(C) The Author(s). 2021, corrected publication 2021. Open Access This article is licensed under a Creative Commons Attribution 4.0 International License, which permits use, sharing, adaptation, distribution and reproduction in any medium or format, as long as you give appropriate credit to the original author(s) and the source, provide a link to the Creative Commons licence, and indicate if changes were made. The images or other third party material in this article are included in the article's Creative Commons licence, unless indicated otherwise in a credit line to the material. If material is not included in the article's Creative Commons licence and your intended use is not permitted by statutory regulation or exceeds the permitted use, you will need to obtain permission directly from the copyright holder. To view a copy of this licence, visit http://creativecommons.org/ licenses/by/4.0/. The Creative Commons Public Domain Dedication waiver (http://creativecommons.org/publicdomain/zero/1. $0 /$ ) applies to the data made available in this article, unless otherwise stated in a credit line to the data. 
of drug resistance in TM, including ethidium bromide (EB), genistein (GE), Congo red (GR), Dimethyl sulfoxide (DMSO), clotrimazole (KM), berberine hydrochloride (BB), Miconazole nitrate salt (MK), Fenarimol (FE), Adriamycin hydrochloride (YA), and Sabouraud dextrose agar (SDA) as reference control. The growth curve, (scanning) electron microscope observation, transcriptome sequencing analysis, and fluorescent quantitative PCR verification were carried out to evaluate them. Proteomics analysis of some substances was also performed. To further analyze the mechanism of drug resistance in TM exposed to these substances, the content of ergosterol was analyzed and the Nile red staining and biofilm thickness were observed through a confocal microscope. The results lay a foundation for scientific prevention and treatment of dermatomycosis caused by TM.

\section{Results}

\section{Growth curve of TM after treatment with different} substances

Figure 1 shows the growth curve of TM after treatment with different substances. The growth curves of the BBand YA- treated group in three different concentrations showed little difference. The growth of TM was slightly stronger at a low concentration of both EB and GR, compared to that of medium and high concentrations, although the differences were minor in GR. The trend of TM's growth curve showed a positive correlation with the concentration of FE, GE, KM, and MK. DM seemed to have a minor effect on the growth of TM.

\section{The morphological changes of TM}

Observation through a TEM showed, that the morphology of TM cells had different degrees of changes following treatment with various substances (Fig. 2). In the SDA-treated group, the morphology of TM was normal. After DMSO treatment, the morphology of TM changed slightly, which was mainly reflected by the appearance of granular substance in its cytoplasm. After BB treatment, TM's membrane became folded and damaged. While in the EB-treated group, the cell membrane of TM became damaged, the nucleus stained intensively, the mitochondria could be clearly identified, and the red color was bright and diffuse after Nile red staining. After FE treatment, TM's cell membrane became damaged, granularlike substances appeared, and the staining turned bright red with red particles. TM treated with GE also had damaged cell membranes. TM cells seemed bulky, granular material appeared, and the cell membrane was damaged following GR treatment. After KM treatment, TM's cell membrane was obviously thickened, the nucleus condensed, and granular substance appeared as well. In addition, in the YA-treated group, the cell membrane became indistinct, mitochondria clearly visible, and the red color was bright and diffuse after staining. Following MK treatment, TM's cell membranes became damaged, the nucleus condensed, the endoplasmic reticulum clearly visible, and after staining, the red color was bright and distributed as fine particles. The fluorescence intensity of the Nile red staining was consistent with confocal microscopy observations; the fat content of TM in the BB-, EB-, FE-, KM-, YA-, and MK-treated groups were significantly higher compared to that of the control group, implying that the results of the Nile red staining were reliable.

\section{SEM observation of morphological changes of TM}

It was observed through SEM that the morphology of TM cells in the groups treated with various substances was different from that of the control group (Fig. 3). In the DMSO-treated group treatment, the morphology of TM changed slightly, which was mainly reflected by shrinking of its shape. TM cells shrank and some of them broke in the BB-treated group. While in the EBtreated group, TM cells were shrunken even more and the hyphae were damaged. In the FE-treated group, the spores of TM cells were deformed or reduced. In the GE-treated group, TM cells were deformed and some spores were broken. The surface of TM cells became smooth in the GR-treated group. In the KM-treated group, the spores of TM became deformed, the mycelium shrunken, and the surface smooth. In the YAtreated group, the spores became smaller and the mycelium shrank. And lastly, TM's cell membrane broke and the spores became deformed in the MK-treated group.

\section{TM transcriptome changes and gene ontology classification results}

According to the Gene Ontology (GO) classification as shown in Fig. 4a, the most enriched GO's in the FEtreated group were biological process, oxidation process, cellular component, integral component of membrane, molecular function, and oxidoreductase activity. The most enriched GO's in the EB-treated group were biological process, oxidation-reduction process, transmembrane transport, cellular component, cytosol, molecular function, and catalytic activity. The most enriched GO's in the KM-treated group were biological process, oxidation-reduction process, transmembrane transport, cellular component, nucleus, molecular function, and catalytic activity. The most enriched GO's in the MKtreated group were biological process, oxidationreduction process, transmembrane transport, cellular component, integral component of membrane, molecular function, and oxidoreductase activity. These data have been deposited in the Sequence Read Archive of the National Center for Biotechnology Information (NCBI) (accession number, GSE162331; [NCBI tracking 

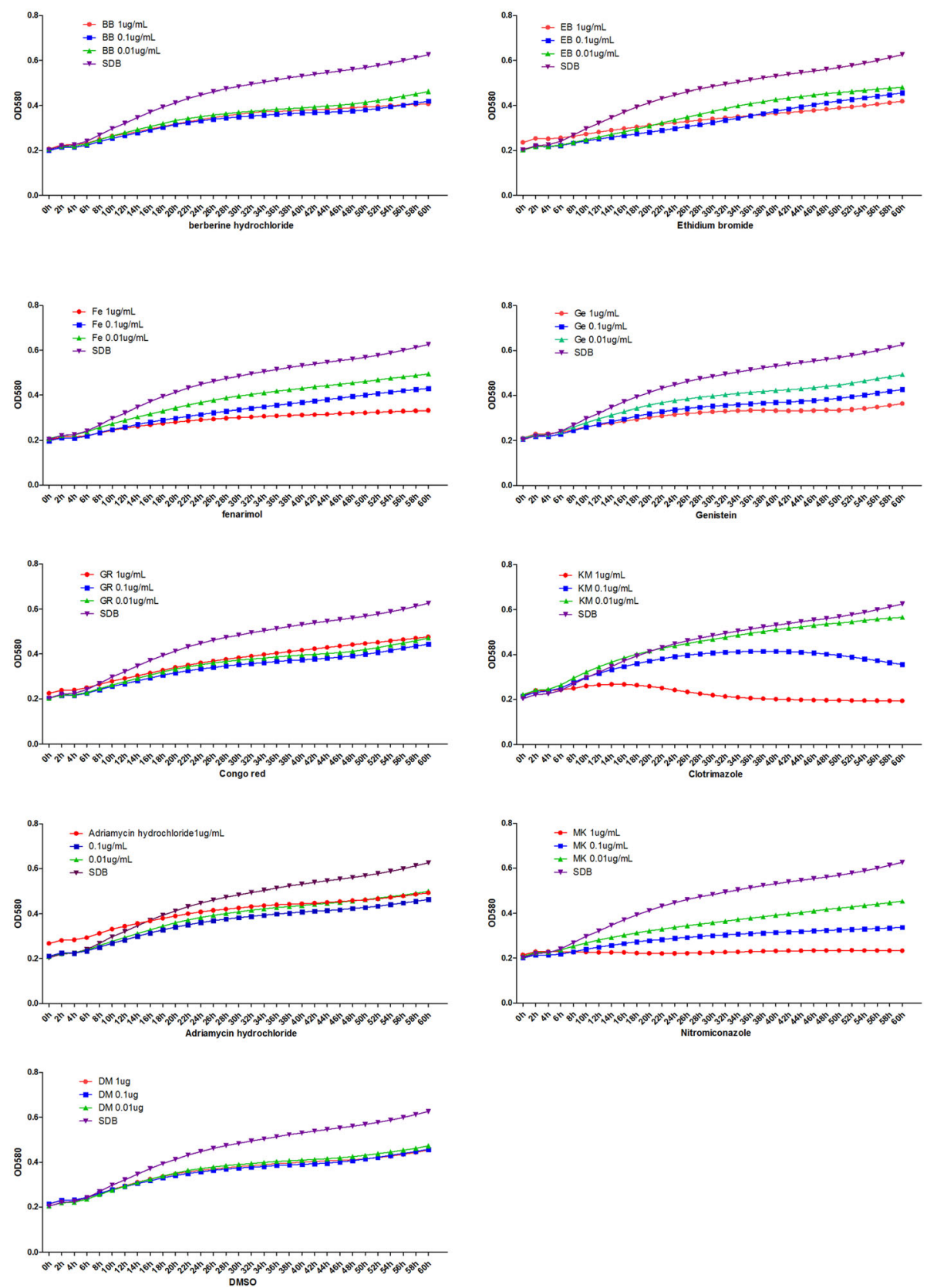

Fig. 1 The effects of varying concentrations of different test substances on TM were determined over time as described in the methods section. Sabouraud dextrose agar (SDA) medium served as a reference control

system \#21491828]). Figure 4b shows the differentially expressed genes (DEGs) of the different groups $(P<$ 0.05). In total 3305 DEGs were detected. Among them, 3 were up-regulated and 9 down-regulated $(P<0.05)$ in the GE-treated group. In the GR-treated group, 16 were up-regulated and 51 down-regulated $(P<0.05)$. The KM-treated group had 578 up-regulated and 615 downregulated genes $(P<0.05)$. The BB-treated group consisted of 15 up-regulated and 102 down-regulated genes
$(P<0.05)$. In the MK-treated group were 202 upregulated and 110 down-regulated genes $(P<0.05)$. The FE-treated group had 156 up-regulated and 153 downregulated genes $(P<0.05)$. The EB-treated group had 157 up-regulated and 200 down-regulated genes $(\mathrm{P}<$ 0.05). The YA-treated group had 408 up-regulated and 34 down-regulated genes $(\mathrm{P}<0.05)$. And lastly, the DMSO-treated group had 169 up-regulated and 327 down-regulated DEGs $(\mathrm{P}<0.05)$. 

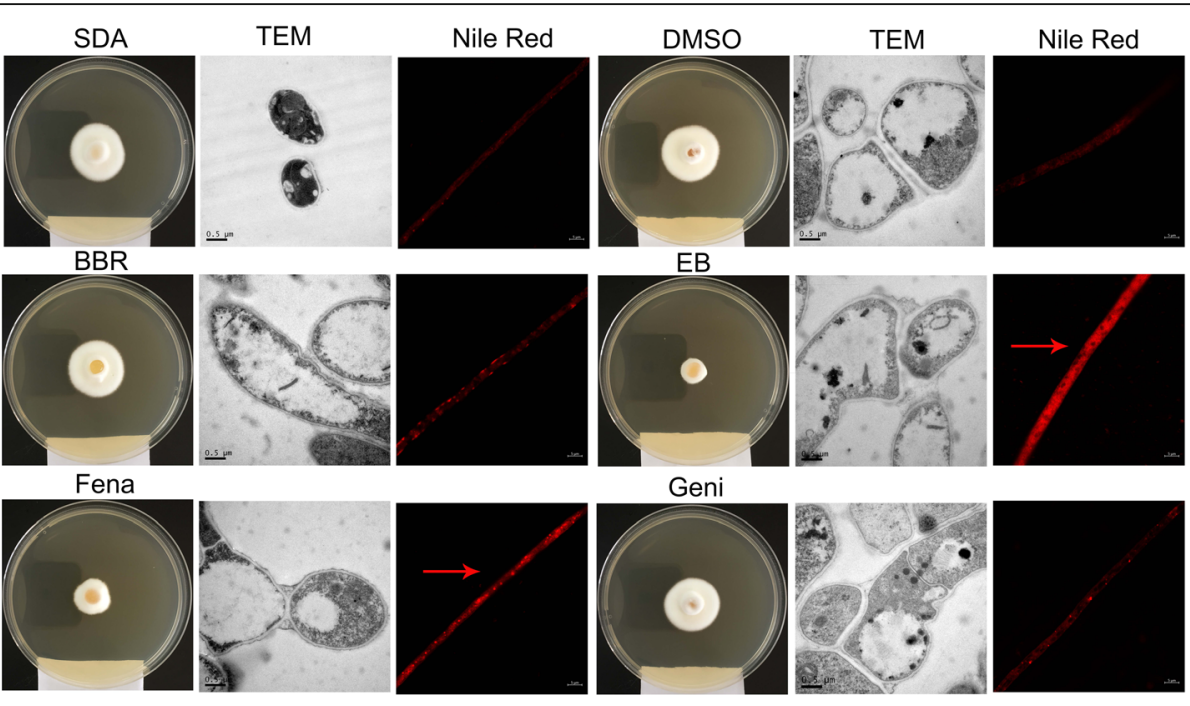

Geni
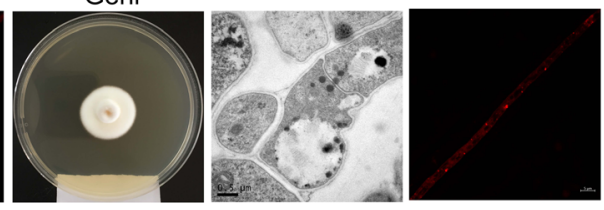

GR
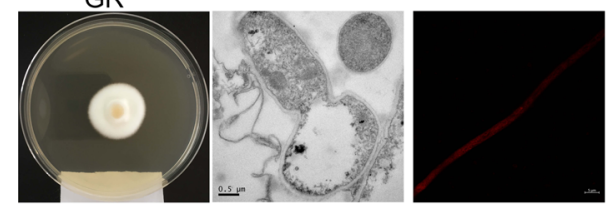

KMZ
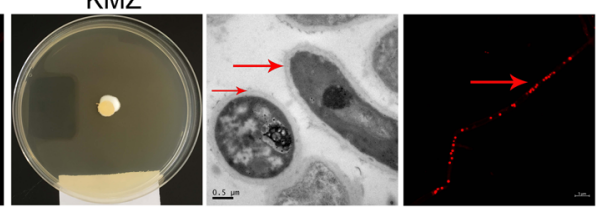

YA

MK
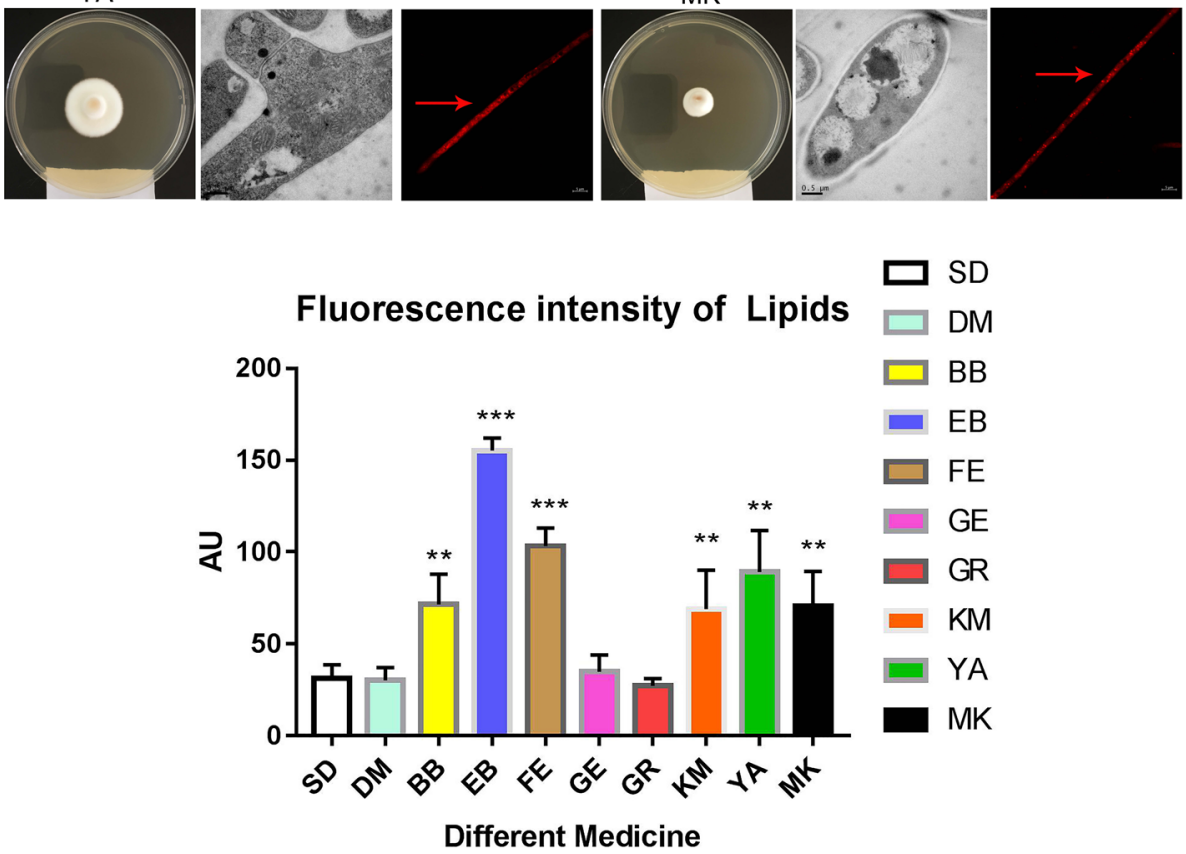

Fig. 2 Observation of morphological changes of TM cells following the addition of test substances under a Zeiss confocal microscope) and, Nile red staininged with Nile red. and observed under a Zeiss confocal microscope. The following test substances were used: Sabouraud dextrose agar (SDA), Dimethyl sulfoxide (DMSO), berberine hydrochloride (BB), ethidium bromide (EB), Fenarimol (FE), genistein (GE), Congo red (GR), clotrimazole (KM), Adriamycin hydrochloride (YA), and Miconazole nitrate salt (MK)

\section{RT-PCR verification of transcriptome}

Comparison of the results of RT-PCR and transcriptome showed that several treatments of AFTA and ELFT genes were completely consistent (Fig. 5). The RT-PCR results of the STPK gene in the GE- and FE-treated group indicated a significant lower fold change compared to the SDA (control) group, although no significant differences were observed between these groups in the transcriptome results (Fig. 5). These results indicate that the transcriptome results were reliable. 


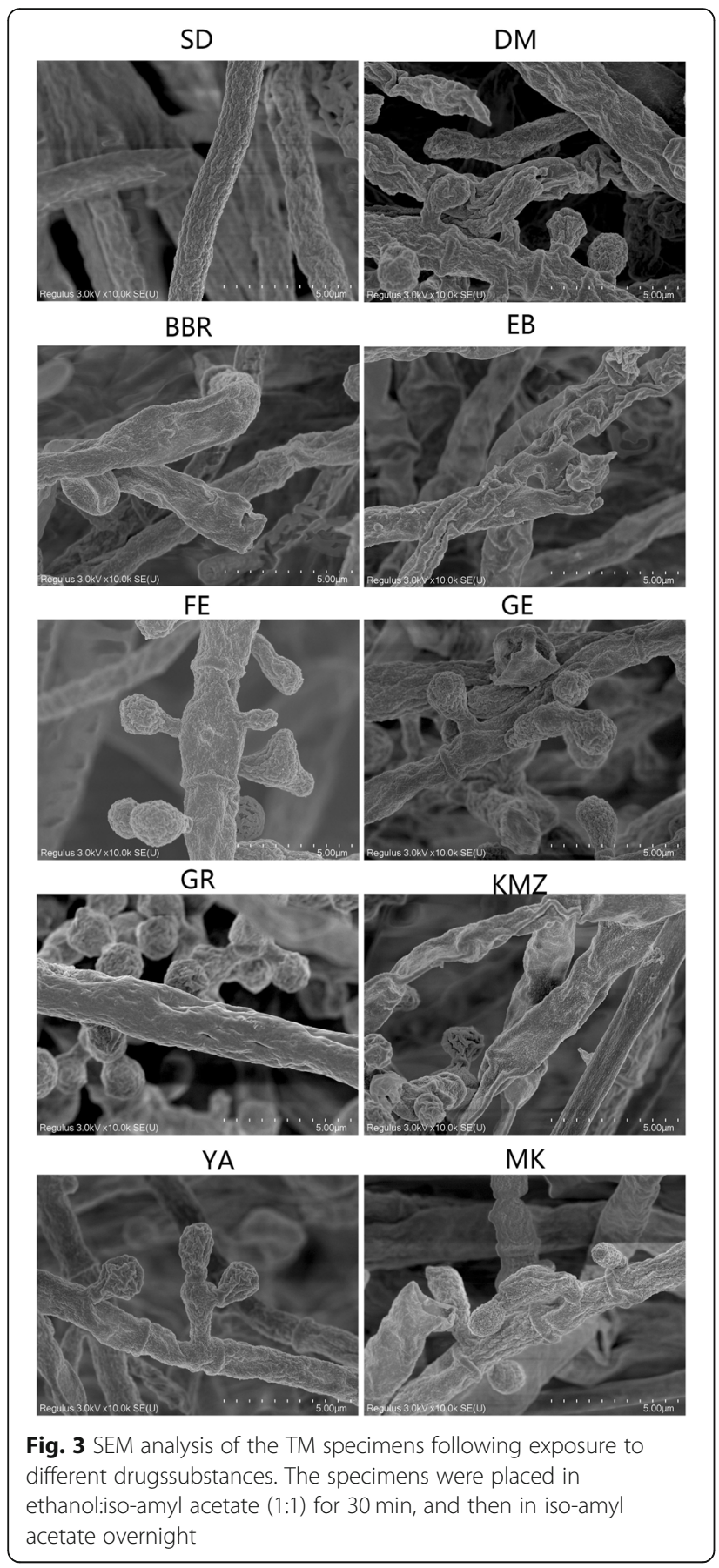

Changes in TM proteomics after KM and BB treatment We identified 847 proteins and 1850 peptides in the KMand BB-treated groups with proteomics. In the BB-treated group, 17 proteins were up-regulated and 13 proteins down-regulated. In the KM-treated group, 74 proteins were up-regulated and 41 proteins down-regulated. In comparison with the BB-treated group, there were 66 up-regulated proteins and 56 down-regulated proteins in the KM-treated group. The selection criteria were $P \leq 0.05$ and fold change
1.5 times the significant difference (Fig. 6a). The following GO terms were used to describe DAPs: "translation," "ribosome," "structural constituent of ribosomal subunit," and "extracellular region" (Fig. 6b). In addition, the DAPs were also classified according to the following three GO categories: "biological process", "cellular component", and "molecular function" (Fig. 6b). COG analysis is based on homologous classification of gene products in the COG database. Our results showed that the most frequently found COG were: "Energy production and conversion", "Amino acid transport and metabolism", "Translation, ribosomal structure and biogenesis", and "Post translational modification, protein turnover, chaperones" (Fig. 6c).

\section{Functional annotation of differentially expressed genes such as KEGG and GO enrichment}

Gene name of methylsterol monooxygenase with Gene ID TMEN_7126 showed significant expression in certain substances treatment groups such as EB-, Fe-, KM-, MK-. The KEGG pathway of TMEN_7126 is belonged with 00100 (Steroid biosynthesis). And Go annotation is GO: 0000254(C-4 methylsterol oxidase activity);GO:0005506(iron ion binding);GO:0005789(endoplasmic reticulum).

Another Gene name of cytochrome P450 with Gene ID TMEN_2906 showed significant expression in certain substances treatment groups such as Fe-, KM-. The KEGG pathway of TMEN_2906 is belonged with 00404(Staurosporine biosynthesis). And Go annotation is GO:0003824(catalytic activity);GO:0005506(iron ion binding);GO:0005575(cellular_component);GO:

0008202(steroid metabolic process);GO:0009055(electron carrier activity);GO:0016705(oxidoreductase activity, acting on paired donors, with incorporation or reduction of molecular oxygen);GO:0020037(heme binding);GO:0055114(oxidation-reduction process).

\section{Determination of ergosterol}

Following treatment with different substances for 5 days, the ergosterol content of TM was determined by HPLC and compared to the SDA (control) group (Fig. 7). The ergosterol content of TM in the BB-, EB-, FE-, and YAtreated groups was significantly higher than that of the SDA (control) group $(* P<0.01)$. The ergosterol content of TM in the KM- and MK-treated groups was higher than that of the SDA (control) group with an increased significant difference $(* * * P<0.001)$.

The expression of cytochrome related gene of TM under $\mathrm{KM}$, the difference of protein under KM and BB treatment, and the results of RT-PCR of CAMP related gene

Figure 8 shows the results of the transcriptome data analysis of methylsterol monooxygenase (ERG25) and cytochrome P450 (CYP450). A significant difference in the expression of the ERG25 gene and CYP450 gene $(P<$ 

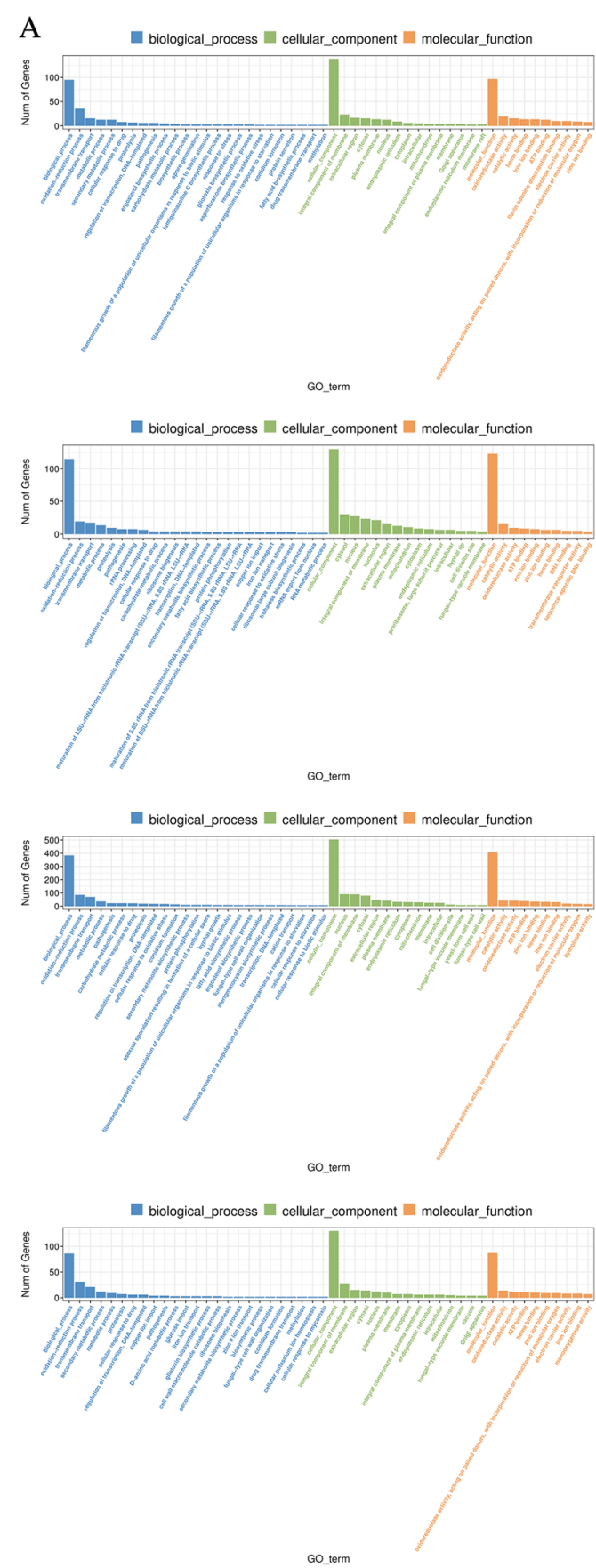

B

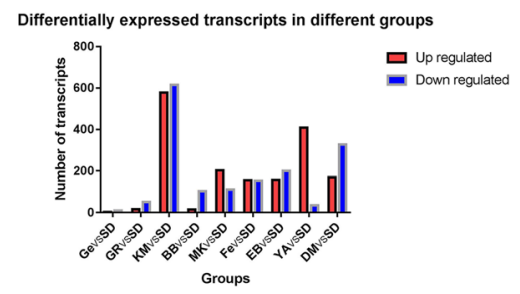

Fig. 4 a: GO classification of TM after exposure to FE, EB, KM and MK in comparison to the control group. $\mathbf{b}$ : Differentially expressed genes (DEGs) of the different groups, of which the KM-treated group consisted of the most up- and down-regulated DEGs. All the results were statistically significant $(P<0.05)$

0.05) was found in the KM-, EB-, FE-, MK-, and YAtreated groups,, which was most obvious in the KM- and FE- treated groups $(P<0.01)$. The relative gene expression of CAMP between the KM-treated group and the SDA control group is shown in Fig. 8e (Table 1). RTPCR showed that the expression of cytochrome related genes including CAMP-dependent protein kinase regulatory subunit (CPKR), cAMP-independent regulatory protein (CIRP), cAMP-dependent protein kinase type 2 (CDPK2), and cAMP-dependent protein kinase catalytic subunit (CDPK) in the KM- and BB- treated groups were significantly higher than those in the SDA control group $(P<0.05)$.

The results of proteomics in the KM-treated group showed that the CYP proteins including CYP450 alkane hydroxylase, CYP450 oxidoreductase, putative (CYP51), and cytochrome b5 heme-binding domain-containing protein were significantly increased compared to the SDA control group $(\mathrm{P}<0.05)$, while no significant difference related to these proteins was found between the BB-treated group and the SDA control group (Table 2).

\section{Biofilm thickness under KM and BB treatment}

The results of the biofilm thickness of TM in the KMand BB-treated groups showed that it gradually increased following exposure to specific concentrations of substances (Fig. 9). The biofilm thickness of TM gradually increased after increasing the concentration of $\mathrm{KM}$ from $0.0625 \mu \mathrm{g} / \mathrm{mL}$ to $0.25 \mu \mathrm{g} / \mathrm{mL}$. The same result was observed when the concentration of $\mathrm{BB}$ was increased from $0.0625 \mathrm{mg} / \mathrm{mL}$ to $0.125 \mathrm{mg} / \mathrm{mL}$.

\section{Discussion}

Fungal infections have been increasing due to various factors, while present antifungal treatments show substantial complications due to their adverse effects and the rise of drug resistance. This continuous rise of fungal strains that are drug-resistant, represented by azole resistance, has become a serious threat to public health, [6]. At present, there are only a few studies on drug resistance of TM, and most studies only focus on functional analysis of some genes or localization of fluorescent proteins [7]. In this study, we selected several representative substances and used transcriptomics and proteomics research to analyze their mechanism of action on TM, and the corresponding strategies of TM in response to them. The results will lay a solid foundation 


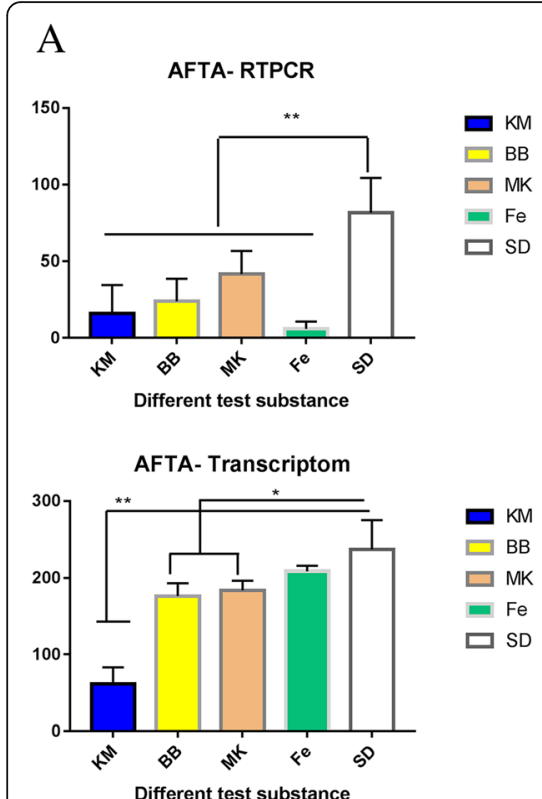

\section{B}
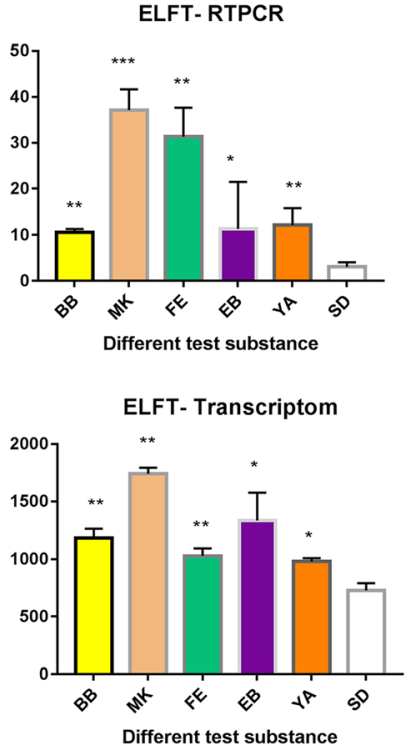

$\mathrm{C}$
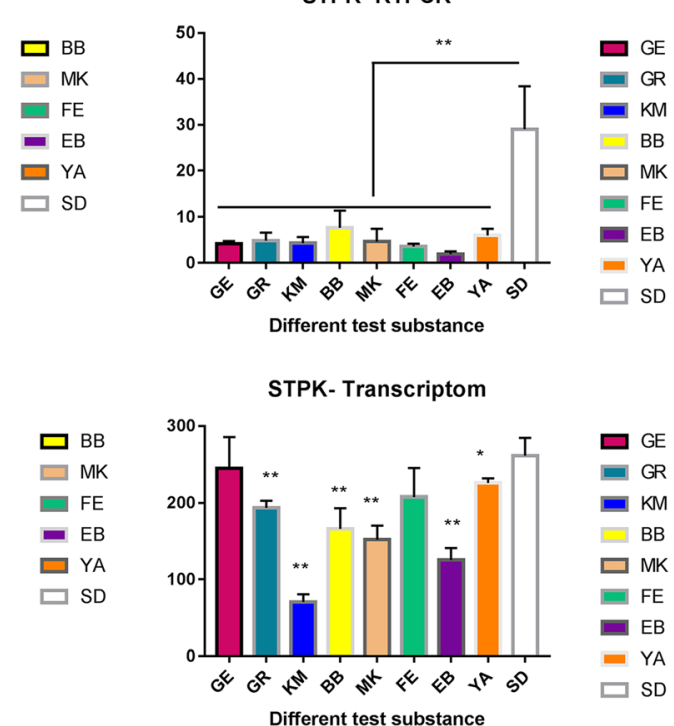

STPK- Transcriptom

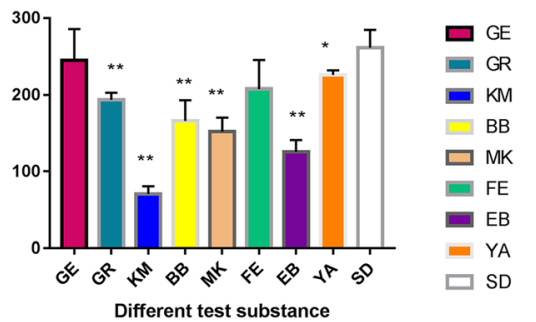

Fig. 5 a shows the results of RT-PCR and transcriptome of the AFTA gene. $\mathbf{b}$ shows the results of RT-PCR and transcriptome of the ELFT gene. c shows the results of RT-PCR and transcriptome of the STPK gene. There were significant differences between the groups exposed to the test substances and SDA control group, ${ }^{*} P<0.05,{ }^{* *}, P<0.01,{ }^{* *}, P<0.001$

for effective control and prevention of dermatomycosis due to TM in the future.

The experimental results of the influence of various substances on the growth curve of TM showed that its growth was obviously inhibited by higher concentrations of these substances. And with increasing concentrations, the antifungal effect also increased. In the subsequent electron microscope results, we observed some interesting phenomena. Some substances had obvious effects on the lipid production of TM at a concentration of $1 \mu \mathrm{g} /$ $\mathrm{mL}$. In particular, FE, EB, GR, KM, YA, and MK, and the results of ergosterol determination were consistent with the fluorescence value of lipids. This confirmed that these drugs have a significant effect on the lipid metabolism of TM. It seems that lipid metabolism is associated with fungal drug resistance. Ergosterol is the primary sterol, found in the plasma membranes of fungi, and plays an important role in membrane integrity and the activity of many enzymes bound to the membrane [8] Inhibiting $14 \alpha$-sterol demethylase results in a buildup of $14 \alpha$-methylated sterols, which leads to a damaged cell membrane with less available ergosterol and modified permeability of the fungal cell [8]. Similar results have been found in Ma's [9] research on the effect of Tebuconazole on Fusarium graminearum, in which the lipid expression gene of Fusarium graminearum was significantly up-regulated. The transcriptome and fluorescence quantitative PCR results of this study showed that the expression of the ERG25 gene, related to fat metabolism, was significantly up-regulated following exposure to KM, EB, FE, MK, and YA, with KM showing the most prominent up-regulation. ERG25 catalyzes oxidation of the ergosterol intermediate 4,4-dimethylzymosterol at the C-4 position, is comprised of three histidinerich clusters, which are common in iron-binding nonheme enzymes, contains an endoplasmic-reticulum retrieval signal, KKXX [10], and is part of the oxidoreductase family [11]. The genes that encode ERG25 have been cloned from the fungus Penicillium chrysogenum (P. chrysogenum), which can produce penicillin. During production of penicillin, the intermediates and enzymes of the penicillin biosynthetic pathway have to be conveyed across multiple membranes. Then, the produced hydrophobic penicillin needs to be delivered into the medium through the peroxisome as well as the plasma membranes. Therefore, transport activities are important in the biosynthesis of penicillin. Ergosterol plays a major part in the permeability of penicillin through the membrane of P. chrysogenum [11]. Previous research indicated that ERG6 was highly up-regulated after treatment with azole fungicides, which had a 37.5 and 50.3 fold increase in expression in Trichophyton rubrum and $C$. albicans, respectively [9]. The results of this study have shown that the expression of ERG25 was significantly up-regulated, especially after treatment with $\mathrm{KM}, \mathrm{EB}, \mathrm{FE}$, and $\mathrm{MK}$, and indicated that the liposome production of TM was significantly enhanced by KM, FE, and MK. These results made us wonder; why does the liposome content of TM only significantly change under the influence of certain substances? There may be three possible 


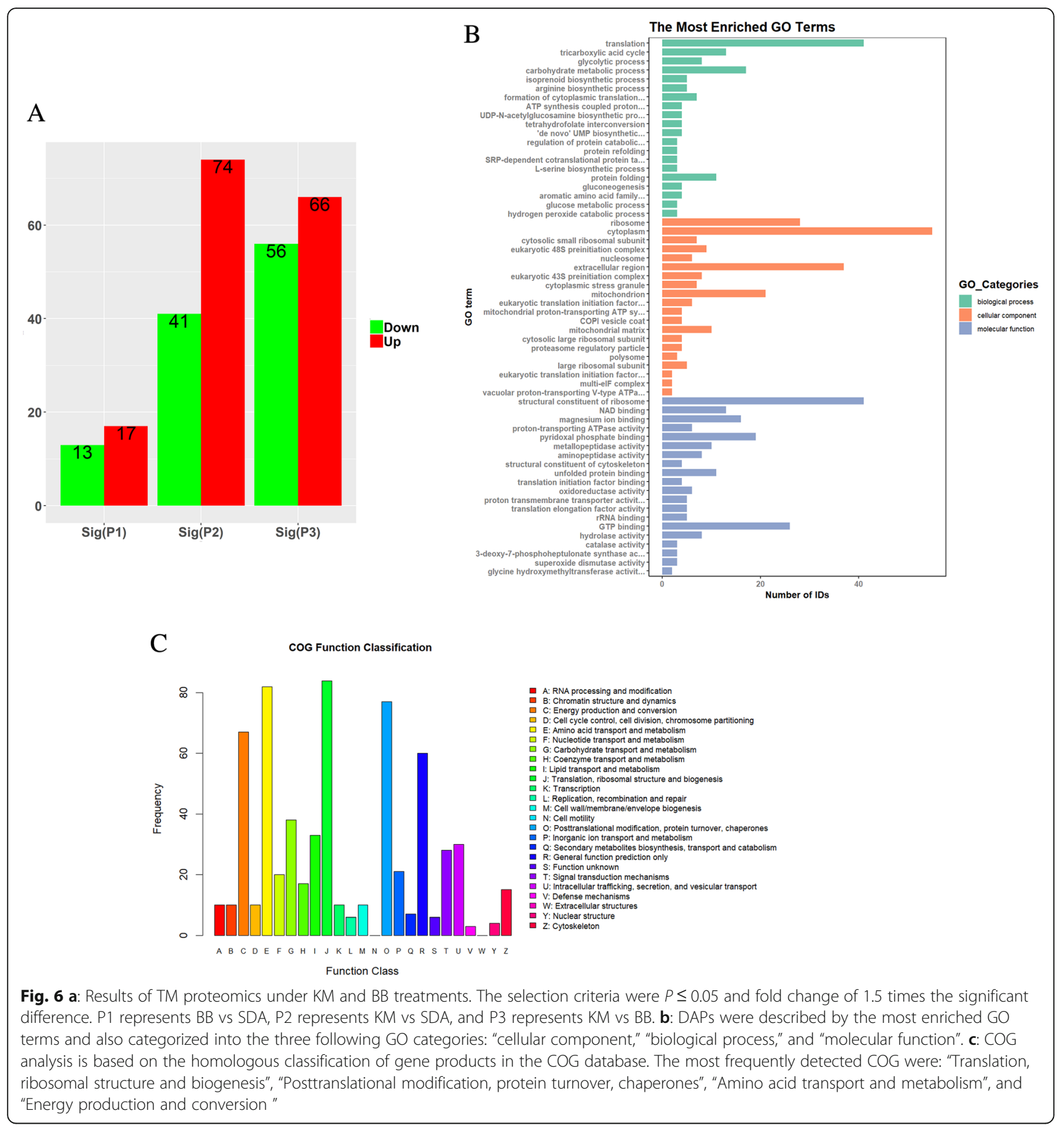

reasons for this. Firstly these substances may promote the upstream genes of ERG in fungi, resulting in their up-regulation. Secondly, liposomes protect fungi to a certain degree. Since the permeability of $P$. chrysogenum is related to the ERG gene, KM, FE, and MK could also induce the permeability of TM's cell membrane. By upregulating the expression of ERG25 and other genes, the content of liposomes in the cell membrane increases, thereby increasing the permeability of these substances, resulting in a reduced accumulation of them, which is a self-protective mechanism of fungi. Finally, the third reason may be that the metabolites of liposomes could neutralize certain chemical substances and fungi can protect themselves by enhancing the metabolism level of liposomes.

In a previous study by $\mathrm{Ma}$ et al. was discovered that the expression of 18 genes that encode components of the cAMP had significantly increased after the fungus was treated with KM [12], which is consistent with previous findings that the ergosterol biosynthetic pathway is 


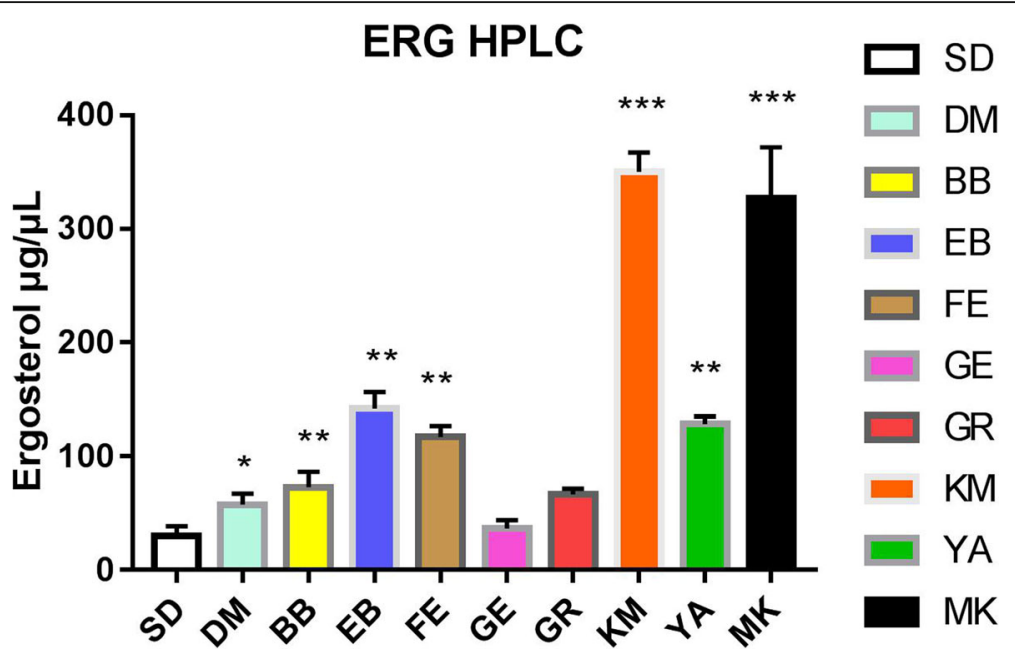

Fig. 7 The ergosterol content of TM after treatment with different substances for 5 days was determined by HPLC and compared to the SDA control group. ${ }^{*} P<0.05$; ${ }^{* *} P<0.01 ;{ }^{* *} P<0.001$. The following test substances were used: Sabouraud dextrose agar (SDA), Dimethyl sulfoxide (DMSO), berberine hydrochloride (BB), ethidium bromide (EB), Fenarimol (FE), genistein (GE), Congo red (GR), clotrimazole (KM), Adriamycin hydrochloride (YA), and Miconazole nitrate salt (MK)

targeted by azole fungicides and reacts to changes in ergosterol levels. According to previous research, fungal CYP450 may play an important part in the detoxification of fungicides or their metabolites [12]. Therefore, it seemed interesting to evaluate if the expression of ERG genes in TM are regulated by this transcription factor. In our study, we found that the CYP450 gene and other related genes were significantly up-regulated by $\mathrm{MK}, \mathrm{FE}$, and especially $\mathrm{KM}$, indicating that it had a regulatory role on cAMP related genes. It has been observed previously that after treating $F$. graminearum with tebuconazole, the two genes, FGSG_03498 and FGSG_09195, which encode the CYP450 monooxygenase, were upregulated by 25.39 and 149.95 folds, respectively [9].

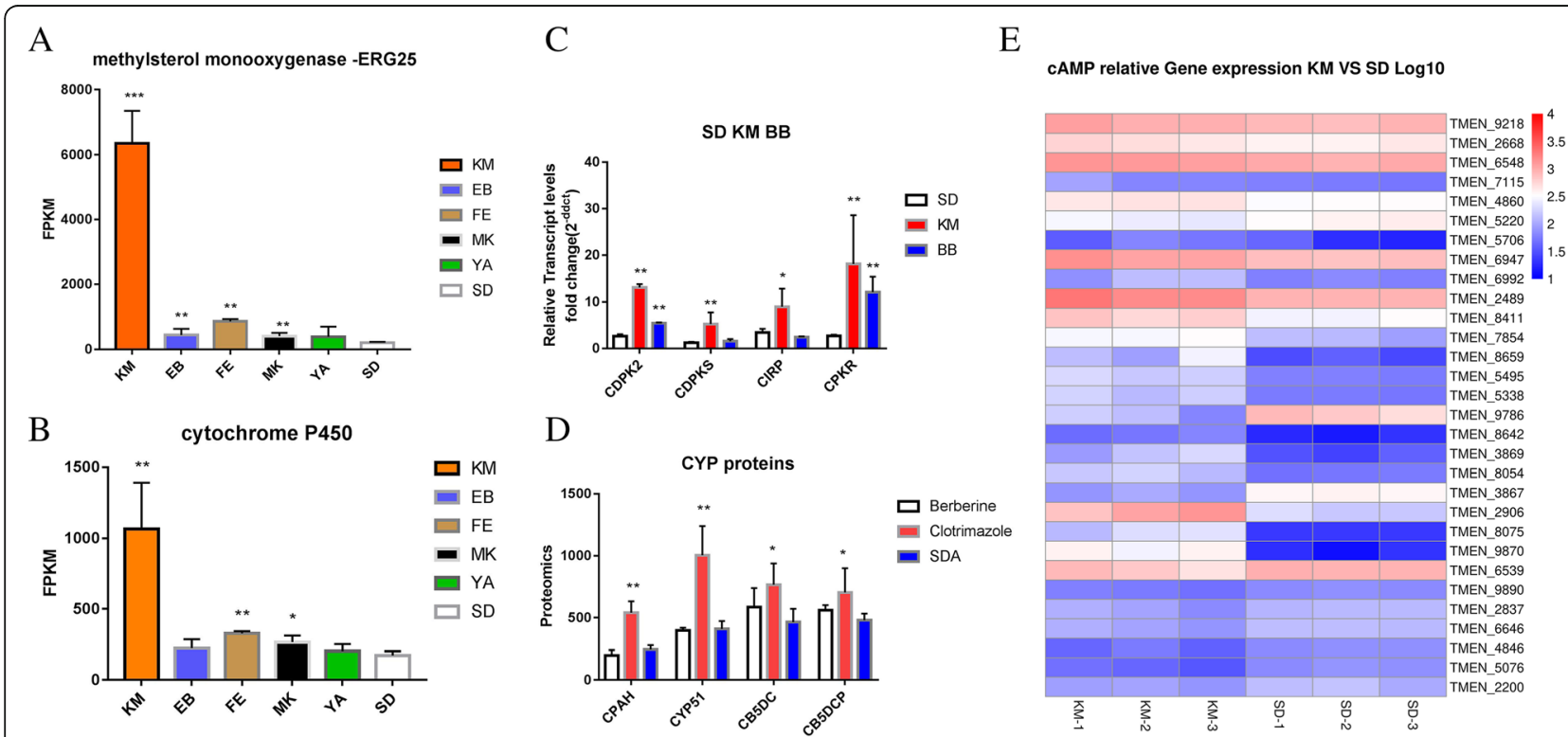

Fig. 8 a: Transcriptome data analysis of methylsetol monooxygenase (ERG25) b: Transcriptome data analysis of Cytochrome P450 (CYP450) c:RTPCR results of CPKR, CIRP, CDPK2 and CDPKS. d: Proteomic data of CYP proteins of TM treated with KM and BB e:Proteomic data of CAMP related proteins in TM treated with KM. Abbreviation means: CPKR means CAMP-dependent protein kinase regulatory subunit, CIRP means CAMPindependent regulatory protein, CDPK2 means CAMP-dependent protein kinase type 2, CDPKS means CAMP-dependent protein kinase catalytic subunit. CPAH means Cytochrome P450 alkane hydroxylase, CYP51 means Cytochrome P450 oxidoreductase, putative (CYP51), CB5DC means Cytochrome b5 heme-binding domain-containing protein, CB5DCP means Cytochrome b5 heme-binding domain-containing protein 2nd 
Table 1 Description table of transcriptome Heatmap

\begin{tabular}{ll}
\hline Gene ID & Description \\
\hline TMEN_9218 & cytochrome c oxidase subunit 6A \\
TMEN_2668 & cytochrome c oxidase polypeptide 5 \\
TMEN_6548 & cytochrome c oxidase subunit 6B \\
TMEN_7115 & cytochrome c oxidase assembly protein \\
TMEN_4860 & cytochrome P450 regulator \\
TMEN_5220 & cytochrome c peroxidase \\
TMEN_5706 & cytochrome P450 \\
TMEN_6947 & cytochrome c oxidase subunit 7A \\
TMEN_6992 & cytochrome P450 \\
TMEN_2489 & cytochrome c oxidase subunit 4 \\
TMEN_8411 & cytochrome b5 \\
TMEN_7854 & cytochrome P450 \\
TMEN_8659 & cytochrome P450 \\
TMEN_5495 & NADPH--cytochrome P450 reductase \\
TMEN_5338 & cytochrome P450 \\
TMEN_9786 & cytochrome P450 \\
TMEN_8642 & cytochrome P450 \\
TMEN_3869 & cytochrome c oxidase-assembly factor \\
TMEN_8054 & cytochrome P450 \\
TMEN_3867 & cytochrome b2 \\
TMEN_2906 & cytochrome P450 \\
TMEN_8075 & cytochrome P450 \\
TMEN_9870 & cytochrome P450 \\
TMEN_6539 & cytochrome P450 \\
TMEN_9890 & cytochrome c \\
TMEN_2837 & cytochrome c oxidase assembly factor \\
TMEN_6646 & cyssembly factor \\
TMEN_4846 & cy
\end{tabular}

Similar results of the reaction of fungi to fungicides have been frequently observed $[12,13]$, indicating the possibility that fungal CYP450 may play an key part in detoxifying fungicides or their metabolites [14].

CYP450s are part of a large hemease superfamily. They are the first set of enzymes labelled as "superfamily," since CYP450s have important roles to play in both the primary and secondary metabolic pathways [15]. These enzymes are important in the catalyzation of oxidative processes of multiple organic substrates and have a key role in steroid conversion and heterogeneous metabolism in the biological domain [6]. Bioactivation of drugs, mediated by CYPs, may cause oxidative stress and result in pathophysiology. The use of drugs may induce hypersensitivity reactions, whereas a metabolic inclination to drug hypersensitivity worsens it. Primarily, various intermediate bioactive products of drug metabolism, mediated by CYPs, are the main cause. Therefore, why do these substances have an up-regulation effect on TM, while the CYP gene itself is part of the regulation of the steroid biosynthesis pathway? Since the regulation of the CYP gene is closely related to fat metabolism and synthesis, CYP related genes will be up-regulated after drug treatment. In a previous study, the impact of the induction of steroid on the resistance of antibiotics targeting the fungal steroid fusidic acid, ramycin; 16-(acetyloxy)$3 \alpha, 11 \alpha$-dihydroxy-29-dammara-17(20),24-dien-21-oicacid, as well as on the reduction of carbonyl, and degeneration of the novel anti-insect agent NKI 42255 (2-(1imidazolyl)-1-(4-methoxyphenyl)-2-methyl-1-propanone) were investigated in Comamonas testosterone, which is a Gram-negative soil bacterium [16]. The results clearly showed that the induction of steroid made it possible for the bacterium to exist in a milieu that would otherwise be deadly if it was uninduced. This indicates that TM up-regulates the steroid biosynthesis gene under the action of certain substances, which benefits the selfsurvival of fungi and therefore TM, in harsh environments by producing excessive steroid.

Biofilm, the tool for survival in fungal colony formation, is a type of three-dimensional structure produced by the microbial community for self-protection. It can adhere to the surface of tissue and is wrapped by extracellular polymer matrix (ECM), which is produced by itself. The formation of biofilm is affected by many factors, including the host's immune state, nutrients, drugs, and physical and chemical factors of the growth environment. Biofilm can lead to fungal drug resistance, and is related to the ERG and CYP [17] genes. The results of a previous study indicate that treatment with fluconazole could affect the metabolism of the fungal structure and cell wall [18, 19], and that these effects could be steadily integrated into the cell wall, after the addition of resistance [20]. Recently, researchers have

Table 2 Description of CYP relative proteins in proteomics experiment

\begin{tabular}{|c|c|c|c|c|c|c|c|c|c|}
\hline & B & & & $\mathrm{K}$ & & & $\mathrm{S}$ & & \\
\hline Cytochrome P450 alkane hydroxylase & 247.4 & 166.8 & 177.8 & 475.2 & 500.1 & 646.9 & 284.4 & 215.7 & 232.2 \\
\hline Cytochrome P450 oxidoreductase, putative (CYP51) & 377.7 & 395.7 & 420.3 & 812.3 & 932.9 & 1266.7 & 479.8 & 391.6 & 355.7 \\
\hline Cytochrome b5 heme-binding domain-containing protein & 480.1 & 515.6 & 762.2 & 769.7 & 936.4 & 595.7 & 580.1 & 444.2 & 367 \\
\hline Cytochrome b5 heme-binding domain-containing protein & 515.3 & 596.2 & 571.4 & 928.3 & 609 & 575.6 & 425.4 & 533.5 & 478.8 \\
\hline
\end{tabular}



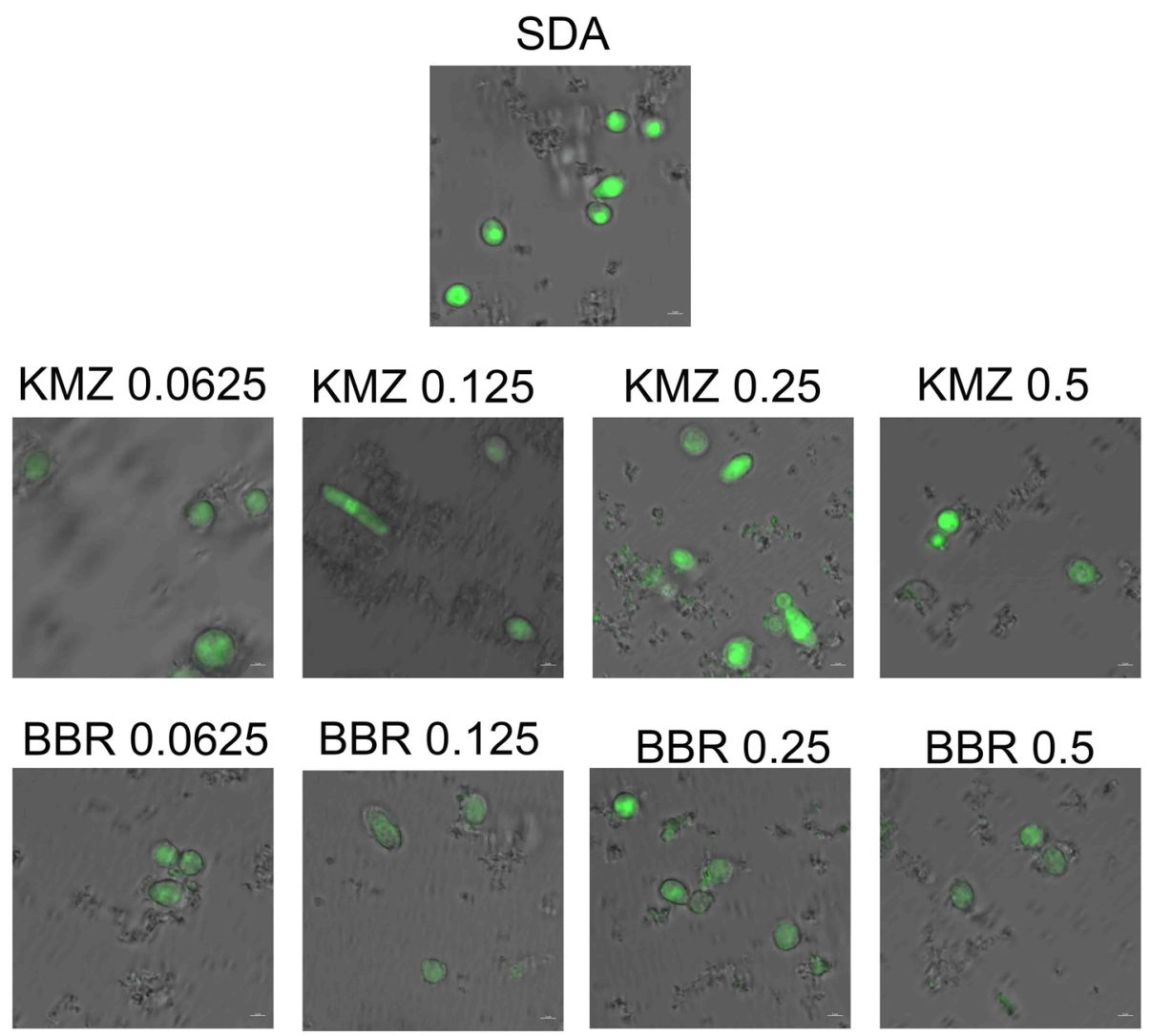

Biofilm

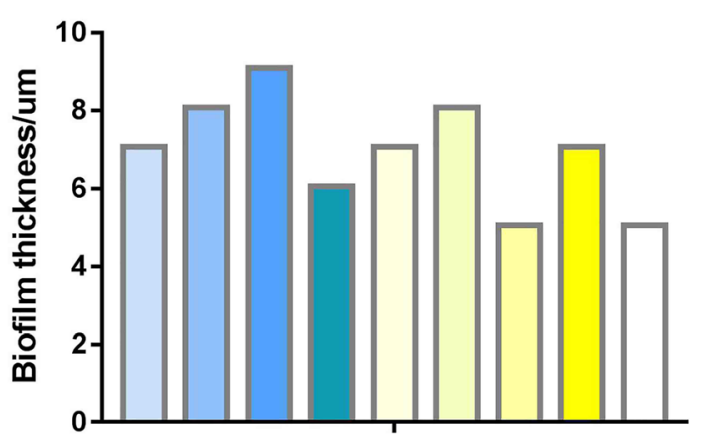

$\mathrm{KM} 0.0625 \mathrm{ug} / \mathrm{mL}$

$\mathrm{KM} 0.125 \mathrm{ug} / \mathrm{mL}$

$\mathrm{KM} 0.25 \mathrm{ug} / \mathrm{mL}$

$\mathrm{KM} 0.5 \mathrm{ug} / \mathrm{mL}$

BBR $0.0625 \mathrm{mg} / \mathrm{mL}$

BBR $0.125 \mathrm{mg} / \mathrm{mL}$

BBR $0.25 \mathrm{mg} / \mathrm{mL}$

BBR $0.5 \mathrm{mg} / \mathrm{mL}$

SDA

Fig. 9 Biofilm thickness following exposure to specific concentrations of KM and BB

examined the cAMP signaling pathway in relation to modifying the sensitivity towards antifungal azoles. $\mathrm{Mu}-$ tants of C. albicans, in the genes that encode the proteins in charge of cAMP synthesis, have shown great hypersensitivity to fluconazole and also to other inhibitors of sterol biosynthesis [21]. Adding cAMP resulted in partial-to-complete reversion of this hypersensitivity. These results indicate that adenylate cyclase inhibitors are capable of modifying antifungal susceptibility.

We found, through transcriptome data and RT-PCR, that the values of elongation factor 3-ELFT (EF3), were significantly up-regulated by $\mathrm{BB}, \mathrm{MK}, \mathrm{FE}, \mathrm{EB}$, and YA. EF3 has a crucial role in the translation of protein [22] and regulates the binding affinities of the deacylated tRNA and the ternary complex to the ribosomal $\mathrm{E}$ and A site, respectively. This way, EF3 seems to keep a balance between the amino acid fidelity and protein translation rate. Since EF3 is a vital protein, repression of the antisense controlled by an inducible promoter, has presented a suitable way to modify the function of the EF3 gene [23]. The existence of HEAT repeats, attribute to increased evidence of the potential role of EF3 in 
targeting protein, and serve as protein-protein interaction domains [22]. Another study showed that a slow growing phenotype of EF3, found in P. infestans, is possibly related to defects in the synthesis of protein. Their results have suggested that with overexpression of EF3 in $P$. infestans, a small elongation defect still exists, which seems to be consistent with the slight sensitivity to antibiotics found in this strain [24]. The up-regulation of EF3 indicates that fungi can improve the synthesis of transport proteins under the stress of drug effects, in order to cope with the threat of drug stimulation.

\section{Conclusions}

In this study, the biofilm of TM was enhanced under the stimulation of certain substances, which is related to the up-regulation of proteins related to the ERG, CYP, and EF3 genes. The results suggests that it is necessary to inhibit the expression of ERG, CYP, and EF3 related genes as well as fat metabolism in order to effectively deal with dermatomycosis caused by TM. These inhibitions lead in turn to the inhibition of biofilm production by the fungus, which can potentially solve the problem of fungal drug resistance in clinical settings.

\section{Methods}

\section{Test strains}

Trichophyton mentagrophytes strains were isolated from rabbits showing symptoms of dermatophytosis, which were provided by the Institute of Internal Medicine, Shaoxing District. The presence of the TM strains was confirmed by The Chinese Academy of Medical Sciences and subsequently grown in SDA at $28^{\circ} \mathrm{C}$ with $60 \%$ moisture. TM were grown in Sabouraud's Glucose Agar Medium (SDA) at $28{ }^{\circ} \mathrm{C}$ with $60 \%$ moisture for 14 days before the experiment.

\section{Growth curve by OD value}

The following substances were used in the experiment: BB (Lot No. 20130306) was produced by Shanghai Yuanye BioTechnology Co., Ltd., China. KM (Lot No. 23593-75-1) was obtained from BaDaTong Medical Company, China. GE (Batch: 02) was purchased from Extrasynthesis Genay Cedex, France. FE (Lot No. C13430000) was purchased from Dr. Ehrenstorfer GmbH Co., Ltd., Germany. GR (Lot No. M180920979), EB (Lot No. C10111224), YA (Lot No. C10223862), and MK (Lot No. C10038681) were purchased from Shanghai Macklin Biochemical Co., Ltd., China. DM (Lot No. 0231) was purchased from Amresco, USA. SDA (Lot No. 403Q021) was purchased from Solarbio Life Sciences, China, whose purity was not lower than $98 \%$.

Concentration and time effects of different substances on TM were established as previously proposed. TM were grown in SDA at $28^{\circ} \mathrm{C}$ with $60 \%$ moisture for 14 days before the experiment. The spores were washed down through the Sabouraud glucose liquid medium (SDB). The washed liquid was filtered through doublelayer filter paper. The density of the suspension determined by a blood cell counter. Mycelium as a homogenate. In short, the fungi were cultured, in presence of $\mathrm{BB}$ $(0.01,0.1$, or $1 \mu \mathrm{g} / \mathrm{mL})$, in a concentration of 30,000 cells/mL [25] at $37^{\circ} \mathrm{C}$ for $0,2,4,6,8,10,12,14,16,18$, $20,22,24,26,28,30,32,34,36,38,40,42,44,46,48$, $50,52,54,56,58$, and $60 \mathrm{~h}$. The growth of TM was observed through a Automatic growth curve analyzer (Bioscreen C, FP-1100-C, Helsinki, Finland) with an OD value of $540 \mathrm{~nm}$ [26].

\section{Ultra-structural analysis by electron microscopy}

TM were grown in SDA at $28^{\circ} \mathrm{C}$ with $60 \%$ moisture for 14 days. All the substances were dissolved in DMSO and prepared with a concentration of $1 \mu \mathrm{g} / \mathrm{mL}$. With a cork bore the fungus was cut into round blocks and inoculated on the drug sensitive include BB, KM, GE, FE, GR, $E B, Y A, M K$ and DM plate to incubate for 10 days.

For TEM, the specimens were first fixated with $2.5 \%$ glutaraldehyde in phosphate buffer $(0.1 \mathrm{M}, \mathrm{pH} 7.0 ;>4 \mathrm{~h})$ and then post-fixated with $1 \% \mathrm{OsO} 4$ in phosphate buffer for 1-2 h. Following washing, graded ethanol was used to dehydrate the specimens and acetone was used to incubate them. After embedding with resin, the specimens were cut into ultra-thin sections on a LEICA EM UC7 ultratome, followed by staining with alkaline lead citrate and uranyl acetate (5-10 min each) and finished with an analysis under a Hitachi Model H-7650 TEM.

For SEM analysis, the specimens were prepared as outlined above for TEM. Then, they were placed for $30 \mathrm{~min}$ in ethanol:isoamyl acetate (1:1) and then isoamyl acetate during the night. After dehydrating the specimens in a Hitachi Model HCP-2 critical point dryer containing liquid $\mathrm{CO}_{2}$, they were covered by gold-palladium with a Hitachi Model E-1010 ion sputter (for 4-5 min) and analyzed with a Hitachi Model TM-1000 SEM.

\section{Nile red staining and ergosterol content determination}

After 5 days of treatment with test substances, the strains were placed on a clean glass plate with a toothpick, stained with Nile red at a concentration of $50 \mu \mathrm{g} / \mathrm{ml}$ with $20 \mu \mathrm{l}$ added, and gently smeared. The staining was observed under a Zeiss confocal microscope and the fluorescence was analyzed by Image J software. The content of ergosterol was determined by high performance liquid chromatography (HPLC). First, $0.1000 \mathrm{~g}$ of sample powder was accurately weighed and grounded by liquid nitrogen, then added to a $2 \mathrm{ml}$ volumetric flask with $7 \mathrm{~m}$ acetonitrile added to it. Next, the mixture was thoroughly mixed, placed into a water bath at $50{ }^{\circ} \mathrm{C}$, taken out after $40 \mathrm{~min}$ for an ultrasonic extraction at room temperature for 30 min, then cooled to room temperature, and fixed with 
acetonitrile. For testing, the mixture was mixed well, then $1 \mathrm{~mL}$ of supernatant was taken and passed through a $0.22 \mu \mathrm{m}$ filter membrane. Test conditions were set as follows: detector: DAD, C18 column: $250 * 4.6 \mathrm{~mm}$; $0.5 \mu \mathrm{m}$, column temperature: $25^{\circ} \mathrm{C}$, wavelength: $281 \mathrm{~nm}$, mobile phase: methanol: water $=80: 20(\mathrm{~V}: \mathrm{V})$, flow rate: $1 \mathrm{ml} / \mathrm{min}$, injection volume: $10 \mu \mathrm{L}$.

\section{Biofilm thickness under KM and BB treatment}

The spore suspension of TM $\left(5 \times 10^{7} \mathrm{CFU} / \mathrm{ml}\right)$ at a logarithmic growth stage was diluted with DMEM basic medium and statically cultured for $6 \mathrm{~h}$ on a round coverslip (BS-14RC) (Biosharp, Life sciences, Anhui, China). Then, BB and KMZ medium was added in the following concentrations for $16 \mathrm{~h}$ of static culture: $0.0625 \mathrm{mg} / \mathrm{mL}, 0.125 \mathrm{mg} / \mathrm{mL}, 0.25$ $\mathrm{mg} / \mathrm{mL}$, and $0.5 \mathrm{mg} / \mathrm{mL}$. After dark staining with the Fun1 cell stain $(10 \mu \mathrm{M}$, Invitrogen, USA) for $1 \mathrm{~h}$, the biofilm of the strain was observed with a laser confocal microscope (Zeiss, LSM880, Germany) at the excitation wavelength of $405 \mathrm{~nm}$ and $410-480 \mathrm{~nm}$. The fluorescent three-dimensional structure map was constructed with Image J software.

\section{mRNA library construction and sequencing}

All the test substances including BB, KM, GE, FE, GR, $\mathrm{EB}, \mathrm{YA}, \mathrm{MK}$ and DM were dissolved in DMSO and prepared at a concentration of $1 \mu \mathrm{g} / \mathrm{mL}$. Three biological replicates were prepared for each condition.

TRIzol Reagent (Invitrogen) was used for extraction of total RNA, per manufacturer's instructions [25]. The total RNA quantity and purity were analysis of Bioanalyzer 2100 and RNA 6000 Nano LabChip Kit (Agilent, CA, USA) with RIN number > 7.0.Approximately $10 \mu \mathrm{g}$ of total RNArepresenting a specific adipose type was subjected to isolate Poly (A) mRNA with poly-T oligoattached magnetic beads (Invitrogen) [27]. Following purification, the mRNA is fragmented into smallpieces using divalent cations under elevated temperature. Then the cleaved RNA fragments werereverse-transcribed to create the final cDNA library in accordance with the protocol for the mRNASeqsample preparation kit (Illumina, San Diego, USA), the average insert size for the paired-endlibraries was $300 \mathrm{bp}( \pm 50 \mathrm{bp})$. And then we performed the paired-end sequencing on an IlluminaHiseq4000 at the (LC Sceiences,USA) following the vendor's recommended protocol.

\section{Sequence and primary analysis}

A cDNA library constructed by technology from the pooled RNA was sequenced run with Illumina 4000 sequence platform. Using the Illumina paired-end RNA-seq approach, we sequenced the transcriptome, generating a total of millon paired-end reads of bp length. This yielded gigabases (Gb) of sequence. Prior to assembly, the low quality reads (1,reads containing sequencing adaptors; 2 , reads containing sequencing primer;3, nucleotide with $\mathrm{q}$ quality score lower than 20) were removed. After that, a total of G bp of cleaned,paired-end reads were produced. The raw sequence data have been submitted to the NCBI Short Read Archive with accession number.

\section{RNA-seq reads mapping}

We aligned reads of sample A and sample B to the UCSC (http://genome.ucsc.edu/) Homo sapiens reference genome using HISAT package, which initially remove a portion of the reads based on quality information accompanying each read and then maps the reads to the reference genome. HISAT allows multiple alignments pe read (up to 20 by default) and a maximum of two mismatchs when mapping the reads to the reference. HISA $T$ build a database of potential splice junctions and confirms these by comparing the previously unmapped reads against the database of putative junctions.

\section{Transcript abundance estimation and differentially expressed testing}

The mapped reads of each sample were assembled using StringTie. Then, all transcriptomes from Samples were merged to reconstruct a comprehensive transcriptome using perl scripts. After the final transcriptome was generated, StringTie and edgeR was used to estimate the expression levels of all transcripts. StringTie was used to perform expression level for mRNAs by calculating FPKM. The differentially expressed mRNAs and genes were selected with log2 (fold change) $>1$ or $\log 2$ (fold change) $<-1$ and with statistical significance $(p$ value $<0.05)$ by $\mathrm{R}$ package.

\section{Real-time PCR}

With a Promega kit (Madison, WI, US), first cDNA was acquired from total RNA $(1 \mu \mathrm{g})$ per manufacturer's instructions. Quantitative RT-PCR was conducted with an ABI StepOnePlus (Applied Biosystems) paired with SYBR Green Supermix (TaKaRa) per manufacturer's instructions. Amplification was conducted at $94{ }^{\circ} \mathrm{C}$ for $10 \mathrm{~m}$, then $40 \mathrm{cy}$ cles at $94^{\circ} \mathrm{C}$ for $15 \mathrm{~s}, 60^{\circ} \mathrm{C}$ for $31 \mathrm{~s}$, and $72^{\circ} \mathrm{C}$ for $1 \mathrm{~m}$. Table 3 contains a description of the primers. Cycle threshold (CT) values were acquired and the $2-\Delta \Delta \mathrm{Ct}$ method was used to analyze the data [28]. 18S, an endogenous housekeeping gene, was used to carry out normalization. The relative expression levels of mRNA from triplicate experiments were expressed as mean \pm SD.

\section{Statistical analysis}

The Duncan's test was performed to compare groups. Statistical analyses were conducted with GraphPad Prism 5 and $P<0.05$ was considered as statistically significant. A Pearson correlation was used to statistically analyze the agreement between qRT-PCR analysis and Illumina RNA-seq analysis. 


\section{Protein extraction and trypsin digestion}

$\mathrm{BB}$ and KM were dissolved in DMSO and prepared at a concentration of $1 \mu \mathrm{g} / \mathrm{mL}$. Trypsin digestion and protein extraction were conducted as described previously [29]. The specimens were first grounded in tubes of $5 \mathrm{~mL}$ and then treated in an ultrasonic processor of high intensity. The solid material obtained through centrifugation at $4{ }^{\circ} \mathrm{C}$ was disposed. The material in the supernatant was first precipitated in 15\% trichloroacetic acid for $2 \mathrm{~h}$ and then placed in pre-cooled acetone. Then, the material that was recovered, was ground first in ammonium bicarbonate buffer, then recovered, and lastly alkylated. Following digestion with trypsin gold (Promega, Madison, WI, USA) multiple types of peptides were produced. To achieve digestion on the first day, we first added trypsin at the highest ratio of $1: 50$, then at a ratio of 1 : 100 for the following $4 \mathrm{~h}$ of digestion. About $100 \mu \mathrm{g}$ of every protein sample was required for TMT labeling.

\section{TMT labeling, high performance liquid chromatography fractionation, and LC-MS/ MS analysis}

We extracted salt from the specimens, labeled it with a Strata X C18 column (Phenomenex, Torrance, CA, USA), and vacuum-dried it through centrifugation. To perform TMT labeling as described previously [29], a 6-plex TMT Kit (Thermo Fisher Scientific, Waltham, MA, USA) was used to reconstitute in 0.5-M triethylammonium bicarbonate buffer. To mark $100 \mu \mathrm{g}$ of the target specimen, one section of TMT reagent was used. Then, the mixture of specimen and reagent was left at room temperature for $2 \mathrm{~h}$. Next, the salt was eliminated and the mixture dehydrated. A model 300

Table 3 Primer sequences for RT-PCR validation

\begin{tabular}{lll}
\hline Name & Sequence & Product length \\
\hline AFTA-up & CAAGTCGAATGAAGCGAGCG & $78 \mathrm{bp}$ \\
AFTA-dn & AGTGACCGAACTGTGCGAAT & \\
ELFT-up & AGACCGCCATCAAGCGTAAA & $92 \mathrm{bp}$ \\
ELFT-dn & CTITGGCAAGAAAGCAGCGA & \\
STPK-up & ATGTAAGGCAAGGAACCGCA & $114 \mathrm{bp}$ \\
STPK-dn & AGAGGTCTTCTCGGGTCTCC & \\
18S-up & AGACCTGGAACCTTGACGC & $73 \mathrm{bp}$ \\
18S-dn & CATCGCTTGTCTCGGCATTG & \\
CPKR-up & CAGCTACCGTCATCTCGACC & $166 \mathrm{bp}$ \\
CPKR-dn & ATCTTGGAGCGCTCATACGG & \\
CIRP-up & CTCCATGACTTGCCGTCTGT & $189 \mathrm{bp}$ \\
CIRP-dn & ATATCACGGCCATGTTCGCA & \\
CDPK2-up & CTGGACTGGGCTGTATGACG & $129 \mathrm{bp}$ \\
CDPK2-dn & GCGGACGAAGGACTCGAAT & \\
CDPKS-up & GGAGCAAGGTATTCCGGTGT & $146 \mathrm{bp}$ \\
CDPKS-dn & CATGGAATAGCCTACCGCGA & \\
\hline
\end{tabular}

Extend C18 column ( $5 \mu \mathrm{m}$ particles, $4.6 \mathrm{~mm}$ ID, 250 mm length, $\mathrm{pH} \mathrm{10;} \mathrm{Agilent,} \mathrm{Santa} \mathrm{Clara,} \mathrm{CA,} \mathrm{USA)}$ was used to partition the specimens based on a 2 to $60 \%$ gradient of acetonitrile supplemented with 10 $\mathrm{mM}$ of ammonium bicarbonate for $80 \mathrm{~min}$. The resolved fractions were combined and water was eliminated. LC-MS/MS analysis was performed at the Jingjie PTM BioLab (Hangzhou) Co., Ltd. (Hangzhou, China) as described previously [29].

\section{Database search}

Thermo Proteome Discovererver. 2.1.0.81 software and the Mascot search engine were used to analyze the MS/ MS data. The unip_Anas_8839 database, retrieved from Uniprot (https://www.uniprot.org/ proteomes/?query = taxonomy:8839), was included in the search., Trypsin/P was used as the cleavage enzyme. The enzyme only allowed two missing cleavages, five alterations, and five charges per peptide. In accordance to previous studies, faults in quality allowance were predetermined as 0.02 $\mathrm{Da}$ for fragment ions and $10 \mathrm{ppm}$ for precursor ions [30, 31]. TMT-6-plex on lysine and carbamido-methylation on cysteine was regarded as stable, and acetylation on protein $\mathrm{N}$-term and oxidation on methionine as changeable elements (Tables S1 and S2). The FDRs of peptides and sites of modification were only allowed an error value of 0.01 . The peptide length was set at a minimum of 7 . The default parameters were predetermined in Thermo Proteome Discoverer. The unique peptide quantities are summarized in Tables S1 and S2. We used raw materials to calculate the intensities of the TMT reporter ion by MS/MS as well as the fold changes of the specimens to perform quantification of TMT. To centralize the quantitative distribution of each specimen, they were mean normalized in the middle range. Then, the protein quantitation was calculated, which served as the median ratio of the corresponding razor or unique peptides of a specific protein. To compare the proteins' accumulation, two-sample and two-sided tests were used. Generally, in statistical analysis, a $P$ value of $<0.05$ was considered and reported as significant. Data on MS proteomics was deposited in the ProteomeXchange Consortium via the PRIDE partner repository (http:// proteomecentral.proteomexchange.org/) with the data set identifier GEO Submission (GSE162331) [NCBI tracking system \#21491828].

\section{Bioinformatic analysis}

GO data was obtained from the UniProt-GOA database (http://www.ebi.ac.uk/GOA/). Although the protein IDs $s$ were adapted to the UniProt IDs, they could simultaneously be labelled to the GO maps. The method of protein sequence alignment was used to note the unannotated proteins. Furthermore, the KEGG database 
(http://www.genome.jp/kegg/) was also reviewed to detect biological and metabolic reactions. KAAS, a KEGG online service tool, was used to mark every protein's KEGG description. Then, the KEGG pathway from another KEGG service product was adapted to map the proteins. To predict the subcellular localizations in each recognized protein, a new version of PSORT/PSORT II (http://www.genscript.com/wolf-psort.html) was used. InterProScan sequence analysis software including the protein sequence alignment method (http://www.ebi.ac. uk/interpro/) was adapted for various analyses of proteins such as its domain.

\section{Supplementary Information}

The online version contains supplementary material available at https://doi. org/10.1186/s12864-021-07520-6

Additional file 1: Table S1. Information of Proteins Unique Sequence ID, Accession, Description and Sequence. (XLS 2984 kb)

Additional file 2: Table S2. Information of Peptide Groups Peptide Group ID, Annotated Sequence, Qvality PEP. (XLS 1255 kb)

\section{Acknowledgements}

Not applicable.

\section{Authors' contributions}

XCW carried out all the experiments; WJY and JQA performed the RT-PCR experiment; XLJ and LZF analyzed the data; HYE, LZF, PY and LK carried out the TEM and SEM experiment; SF, WQ and LY carried out the biofilm experiment; and BGL and XCW designed the experiments. All authors read and approved the final manuscript.

\section{Funding}

This study was supported by a grant from the China agricultural research system (Code No.nycytx-44-3-2) and Zhejiang Provincial Natural Science Foundation Project (LQ12C18002) and Biohealth inter-collaboration project of Zhejiang Academy of Agricultural Sciences.

\section{Availability of data and materials}

The raw transcriptome data has been deposited in the Sequence Read Archive of the National Center for Biotechnology Information (NCBI) (accession No. GSE162331 and [NCBI tracking system \#21491828]). The datasets used and/or analysed during the current study are also available from the corresponding author on reasonable request.

\section{Declarations}

Ethics approval and consent to participate Not applicable.

\section{Consent for publication}

Not applicable.

\section{Competing interests}

The authors declare that they have no competing interests.

\section{Author details}

${ }^{1}$ Institute of Animal Husbandry and Veterinary Science, Zhejiang Academy of Agricultural Sciences, Hangzhou, China. ${ }^{2}$ State Key Laboratory for Managing Biotic and Chemical Treats to the Quality and Safety of Agro-products, Institute of Plant Protection and Microbiology, Zhejiang Academy of Agricultural Sciences, Hangzhou 310021, China. ${ }^{3}$ Central Laboratory of Zhejiang Academy of Agricultural Sciences, Zhejiang Academy of Agricultural Sciences, Hangzhou, China. ${ }^{4}$ National Clinical Research Center for Infectious Diseases, The Department of Infectious diseases, State Key Laboratory for
Diagnosis and Treatment of Infectious Diseases, The First Affiliated Hospital, College of Medicine, Zhejiang University, 79 Qingchun Road, Hangzhou 310003, China. ${ }^{5}$ College of Life Sciences, China Metrology University, Hangzhou, China.

Received: 15 January 2021 Accepted: 8 March 2021

Published online: 07 April 2021

\section{References}

1. Cafarchia C, Weigl S, Figueredo LA, Otranto DJVM. Molecular identification and phylogenesis of dermatophytes isolated from rabbit farms and rabbit farm workers. Fungal Genet Biol. 2012;154(3-4):395-402.

2. Microbial resistance and resilience in response to environmental changes under the higher intensity of human activities than global average level. Glob Change Biol. 2020, 26(4).

3. Shi Y, Niu QF, Yu XX, Jia XL, Wang J, Lin DG. Jin YP. Assessment of the function of SUB6 in the pathogenic dermatophyte Trichophyton mentagrophytes. Medical mycology. 2015;54. https://doi.org/10.1093/mmy/ myv071.

4. Yamada T, Makimura K, Hisajima T, Ito M, Umeda Y, Abe S. Genetic transformation of the dermatophyte, Trichophyton mentagrophytes, based on the use of G418 resistance as a dominant selectable marker. J Dermatol Sci. 2008;49(1):53-61

5. Xinke Z, Yanchun W, Wanyi C, Yao S, Si C, Degui L, Yipeng JJMM. Metalloprotease genes of Trichophyton mentagrophytes are important for pathogenicity. Med Mycol. 2014:52:36-45.

6. Z Zhang J, Li L, Lv Q, Yan L, Wang Y, Jiang YJO. The fungal CYP51s: their functions, Structures, Related Drug Resistance, and Inhibitors. Front Microbiol. 2019;10:691.

7. Chenwen X, Ling L, Limin L, Yan L, Qiang W, Quan'An J, Guochang S, Fucheng L, Jiaoyu W, Guolian B. Application of the red fluorescent protein mCherry in mycelial labeling and organelle tracing in the dermatophyte Trichophyton mentagrophytes. FEMS Microbiol Lett. 2018;365(6). https://doi. org/10.1093/femsle/fny006

8. Casalinuovo I, Di Francesco P, Garaci E. Fluconazole resistance in Candida albicans: a review of mechanisms. Sciences P. 2004;8:69-78.

9. Yun Y, Yin D, Dawood DH, Liu X, Chen Y, Ma Z. Functional characterization of FgERG3 and FgERG5 associated with ergosterol biosynthesis, vegetative differentiation and virulence of Fusarium graminearum. Fungal Genet Biol. 2014;68:60-70. https://doi.org/10.1016/j.fgb.2014.04.010.

10. Kennedy MA, Johnson TA, Lees ND, Barbuch R, Eckstein JA, Bard MJL. Cloning and sequencing of the Candida albicans C -4 sterol methyl oxidase gene (ERG25) and expression of an ERG25 conditional lethal mutation in Saccharomyces cerevisiae. Lipids. 2000;35(3):257-62.

11. Kristan K, Rižner TL. Steroid-transforming enzymes in fungi. Biol M. 2012; 129(1-2):79-91.

12. Kagan IA, Michel A, Prause A, Scheffler BE, Pace P, Duke SO. Gene transcription profiles of Saccharomyces cerevisiae after treatment with plant protection fungicides that inhibit ergosterol biosynthesis. Physiology. 2005; 82(2):133-53.

13. Ferreira MEdS, Malavazi I, Savoldi M, Brakhage AA, Goldman MHS, Kim HS, Nierman WC, Goldman GH. Transcriptome analysis of Aspergillus fumigatus exposed to voriconazole. Pestic Biochem Physiol. 2006;50(1):32.

14. Khan R, Tan R, Mariscal AG, Straney DJMM. A binuclear zinc transcription factor binds the host isoflavonoid-responsive element in a fungal cytochrome p450 gene responsible for detoxification. Curr Genet. 2010; 49(1):117-30.

15. Lamb DC, Waterman MR, Kelly SL, Guenaerich FP. Cytochromes P450 and drug discovery. Mol Microbiol. 2007;18(6):504-12.

16. Oppermann UCT, Belai I, Maser E. Antibiotic resistance and enhanced insecticide catabolism as consequences of steroid induction in the gramnegative bacterium Comamonas testosteroni. Biology M. 1996;58(2):217.

17. Rivero-Menendez O, Alastruey-Izquierdo A, Mellado E, Cuenca-Estrella M Triazole resistance in Aspergillus spp.: a worldwide problem? J Steroid Biochem Mol Biol. 2016;2(3):21.

18. Hazen KC, Gerald M, Elizabeth C, Giangqin W. Influence of fluconazole at subinhibitory concentrations on cell surface hydrophobicity and phagocytosis of Candida albicans. J Fungi. 2000;1:89-94.

19. Pujol C, Reynes J, Renaud F, Raymond M, Tibayrenc M, Ayala FJ, Janbon F, Bastide MJ. The yeast Candida albicans has a clonal mode of reproduction 
in a population of infected human immunodeficiency virus-positive patients. FEMS Microbiol Lett. 1993;90(20):9456-9.

20. Angiolella L, Micocci MM, D'Alessio S, Girolamo A, Maras B, Cassone A. Identification of Major Glucan-Associated Cell Wall Proteins of Candida albicans and Their Role in Fluconazole Resistance. Proc Natl Acad Sci. 2002; 46(6):1688-94.

21. Pooja J, Indira A, Thomas E. Cyclic AMP signaling pathway modulates susceptibility of candida species and Saccharomyces cerevisiae to antifungal azoles and other sterol biosynthesis inhibitors. Agents Chemother. Lipids. 2000;35:257-62.

22. Liu M, Gelli AJEC. Elongation factor 3, EF3, associates with the Calcium Channel Cch1 and targets Cch1 to the plasma membrane in Cryptococcus neoformans; 2008.

23. Gorlach JM, Mcdade HC, Perfect JR, Cox GM. Antisense repression in Cryptococcus neoformans as a laboratory tool and potential antifungal strategy. Eukaryot Cell. 2002;148(1):213-9.

24. Mateyak MK, Pupek JK, Garino AE, Knapp MCC, Dunaway SJPO.

Demonstration of translation elongation factor 3 activity from a non-fungal species. Phytophthora infestans. 2018;13(1):e0190524.

25. Xiao C, Liu Y, Wei Q, Ji Q, Li K, Pan L, Bao GJM. Inhibitory Effects of Berberine Hydrochloride on Trichophyton mentagrophytes and the Underlying Mechanisms. Plos One. 2019;24(4):742.

26. Li K-H, Yu Y-H, Dong H-J, Zhang W-B, Ma J-C, Wang H-H. Biological functions of ilvC in branched-chain fatty acid synthesis and diffusible signal factor family production in Xanthomonas campestris. Mol. 2017;8:2486.

27. Bing, Shengming S, Jian Z, Yanli, Zhang W, XJ. Transcriptome profiling and histology changes in juvenile blunt snout bream (Megalobrama amblycephala) liver tissue in response to acute thermal stress. Genomics. Front Microbiol. 2017;8:2486.

28. Livak KJ, Schmittgen TD. Analysis of relative gene expression data using real-time quantitative $P C R$ and the $2-\Delta \Delta C T$ method. Mol. 2001;25(4):402-8.

29. Yun T, Hua JG, Ye WC, Yu B, Ni Z, Chen L, Zhang C.Comparative proteomic analysis revealed complex responses to classical/novel duck reovirus infections in the spleen tissue of Cairna moschata. J Proteomics. 2019;193: $162-72$.

30. Chen CY, Rao SS, Lu R, Hu XK, Tan YJ, Yin H, Luo J, Liu YW, Hao Y, Jie HJT. Exosomal DMBT1 from human urine-derived stem cells facilitates diabetic wound repair by promoting angiogenesis. Methods. 2018;8(6):1607-23.

31. Li Y, Luo Z, Wu X, Zhu J, Yu K, Jin Y, Zhang Z, Zhao S, Zho L: Proteomic analyses of cysteine redox in high-fat-fed and fasted mouse livers: implications for liver metabolic homeostasis. Methods. J Proteome Res. 2018;17:129-40

\section{Publisher's Note}

Springer Nature remains neutral with regard to jurisdictional claims in published maps and institutional affiliations.

Ready to submit your research? Choose BMC and benefit from:

- fast, convenient online submission

- thorough peer review by experienced researchers in your field

- rapid publication on acceptance

- support for research data, including large and complex data types

- gold Open Access which fosters wider collaboration and increased citations

- maximum visibility for your research: over $100 \mathrm{M}$ website views per year

At BMC, research is always in progress.

Learn more biomedcentral.com/submissions 